\title{
Autoradiographic Quantification of Muscarinic Cholinergic Synaptic Markers in Bat, Shrew, and Rat Brain*
}

\author{
Roger L. Albin, ${ }^{1,2}$ Morgan M. Howland, ${ }^{3}$ Donald S. Higgins, ${ }^{1}$ and Kirk A. Frey ${ }^{1,2,3,4,5}$
}

(Accepted October 5, 1993)

\begin{abstract}
We employed radioligand binding autoradiography to determine the distributions of pre- and postsynaptic cholinergic radioligand binding sites in the brains of two species of bat, one species of shrew, and the rat. High affinity choline uptake sites were measured with $\left[{ }^{3} \mathrm{H}\right]$ hemicholinium, and presynaptic cholinergic vesicles were identified with $\left[{ }^{3} \mathrm{H}\right]$ vesamicol. Muscarinic cholinergic receptors were determined with $\left[{ }^{3} \mathrm{H}\right]$ scopolamine. The distribution patterns of the three cholinergic markers were similar in all species examined, and identified known major cholinergic pathways on the basis of enrichments in both pre- and postsynaptic markers. In addition, there was excellent agreement, both within and across species, in the regional distributions of the two presynaptic cholinergic markers. Our results indicate that pharmacological identifiers of cholinergic pathways and synapses, including the cholinergic vesicle transport site, and the organizations of central nervous system cholinergic pathways are phylogenetically conserved among eutherian mammals.
\end{abstract}

KEY WORDS: Vesamicol; hemicholinium-3; scopolamine; muscarinic receptor; high-affinity choline uptake; cholinergic vesicle.

\section{INTRODUCTION}

The anatomy and connections of cholinergic neurons within the central nervous system have been the subject of intense scrutiny within the last decade. Anatomic, pharmacologic, and human clinical studies have emphasized the importance of cholinergic mechanisms in memory and cognition $(1,2)$, motor performance (3), and in the regulation of sleep and arousal (4). From a comparative perspective, acetylcholine is utilized as a neurotransmitter throughout the animal kingdom (see

\footnotetext{
${ }^{1}$ Dept. of Neurology.

${ }^{2}$ Neuroscience Program.

${ }^{3}$ Mental Health Research Institute, and

${ }^{4}$ Division of Nuclear Medicine The University of Michigan, Ann Arbor, MI

${ }^{5}$ Address reprint requests to: Kirk A. Frey, M.D., Ph.D., The University of Michigan Hospitals, B1G 412-0028 AGH, 1500 E. Medical Center Dr., Ann Arbor, MI 48109-0028.

* Special issue dedicated to Dr. Bernard W. Agranoff.
}

Wachtler (5) for review). While cholinergic pathways have been extensively studied in select mammals (6-9), there is little data on the organization of cholinergic pathways in other vertebrates.

The available data suggest that all vertebrates examined to date possess a ventral complex of cholinergic neurons homologous to the mammalian magnocellular basal forebrain nuclei. This region is implicated in the provision of most cholinergic innervation of the cerebral cortex (10). Studies of some reptiles, however, have shown that the distribution of cholinergic neurons and neuropil within the striatal and hippocampal homologues differs from that found in mammals (11-13). In addition, recent studies indicate that the regulation of striatal cholinergic activity in reptiles differs from that found in rats $(14,15)$. Due to the limited number of mammals and non-mammalian vertebrates studied, it is unclear whether these anatomic and functional distinctions reflect differences between classes of vertebrates or, alternatively, species variations within classes. In the present studies, 
we address one aspect of this issue by employing radioligand binding autoradiography to quantify the distribution of pre- and postsynaptic cholinergic markers in the brains of previously unstudied eutherian mammals. These results are compared with data obtained simultaneously in rats. In addition, the distribution of a relatively new putative presynaptic cholinergic marker, the binding of $\left[{ }^{3} \mathrm{H}\right]$ vesamicol to the presynaptic cholinergic vesicle (16), is evaluated in direct comparison to the more traditionally-employed distribution of sodium-dependent, high-affinity transmembrane choline uptake sites, identified by $\left[{ }^{3} \mathrm{H}\right]$ hemicholinium-3 binding (17).

\section{EXPERIMENTAL PROCEDURE}

Materials. Tritiated scopolamine ( $30 \mathrm{Ci} / \mathrm{mmol})$, obtained by custom labelling, and tritium-sensitive X-ray film (Hyperfilm) were purchased from Amersham (Arlington Hts, IL). Tritiated vesamicol (49 $\mathrm{Ci} / \mathrm{mmol})$ and $\left[{ }^{3} \mathrm{H}\right]$ hemicholinium-3 $(137 \mathrm{Ci} / \mathrm{mmol})$ were purchased from DuPont-New England Nuclear (Boston, MA).

Animals and Tissue Preparation. Four Egyptian Tomb bats (Rousettus egypticus), four Whispering bats (Carrollia perspicalata), two Short-Tailed shrews (Blarina brevicauda), and four Sprague-Dawley rats (Rattus rattus) were used. Arimals were decapitated, the brains rapidly extracted from the cranial vault, frozen in crushed dry ice, coated with frozen section embedding matrix (Lipshaw, Detroit, MI), and stored at $-70^{\circ} \mathrm{C}$. At the time of sectioning, brains were warmed to $-20^{\circ} \mathrm{C}$, and 20 micron-thick coronal sections were thaw-mounted onto gelatin-coated slides, air-dried, and stored at $-70^{\circ} \mathrm{C}$ until assay.

Ligand Binding Autoradiography. Binding assays were performed on adjacent sections from selected levels of each brain. Each assay consisted of: 1) a 5 min pre-incubation at $25^{\circ} \mathrm{C}$ to remove endogenous ligands; 2) incubation with labelled ligand at $25^{\circ} \mathrm{C}$; and 3) post-wash at $4^{\circ} \mathrm{C}$ to reduce non-specific binding. Phosphate buffered saline containing EDTA $\left(137 \mathrm{mM} \mathrm{NaCl}, 3 \mathrm{mM} \mathrm{KCl}, 8 \mathrm{mM} \mathrm{Na}_{2} \mathrm{HPO}_{4}, 1.5 \mathrm{mM}\right.$ $\mathrm{KH}_{2} \mathrm{PO}_{4}$ and $1 \mathrm{mM}$ EDTA; $\mathrm{pH} 7.4$ ) was used in all assays.

Muscarinic receptors were labeled after incubation in $10 \mathrm{nM}$ $\left[{ }^{3} \mathrm{H}\right]$ scopolamine for 30 minutes and received a 10 minute post-wash (18). Cholinergic vesicle transport sites were labeled after incubation in $20 \mathrm{nM}\left[{ }^{3} \mathrm{H}\right]$ vesamicol for 60 minutes, followed by a 2 minute postwash $(19,20)$. High affinity, sodium-dependent transmembrane choline uptake sites were labeled after incubation in $10 \mathrm{nM}\left[{ }^{3} \mathrm{H}\right]$ hemicholinium3 for 120 minutes, followed by a 2 minute post-wash $(21,22)$.

Sections were air-dried and apposed to tritium-sensitive film in light tight X-ray cassettes. Standards containing known amounts of radioactivity were co-exposed with the sections. Films werc exposed for 2 (scopolamine and vesamicol) or 4 (hemicholinium-3) weeks, and then developed in Kodak D-19.

Data Analysis. Autoradiograms were analyzed by computer-assisted densitometry (MCID System, Imaging Research; St. Catherines, ONT). Film optical density was converted to tissue radioactivity concentration using a regression curve derived from radioactive standards exposed on each film (23). Brain regions identified included areas with anticipated high and low levels of cholinergic markers, on the basis of prior rodent and primate studies, and included the interpeduncular nucleus, basolateral amygdala, striatum, dentate gyrus, CA1 field of the hippocampus, $\mathrm{CA} 3$ field of the hippocampus, frontal cortex, occipital cortex, superficial layers of the superior colliculus, thalamus, and cerebellar cortex. In the two species of bat, striatal measurements were determined from the average of the caudate nucleus and the putamen.

Phylogenetic similarities in the regional distributions of binding sites were explored with the use of regression analysis, performed between species. As cholinergic pathways of the rat have been studied extensively, regional binding levels in both species of bats and shrew brain were compared with those of the rat. In addition, the patterns of the three putative cholinergic markers were compared with one another within each species to assess relationships between the two presynaptic sites, and between pre- and postsynaptic indices. Statistical analyses of regional binding correlations were accomplished employing a linear regression model (SigmaStat program, Jandel Scientific, San Rafael, CA).

\section{RESULTS}

Presynaptic Cholinergic Marker Distributions. Similar patterns of individual cholinergic marker distributions were observed across the brains of each species examined (Table I; Figs. 2-5). In addition to cross-species similarity in $\left[{ }^{3} \mathrm{H}\right]$ hemicholinium-3 and $\left[{ }^{3} \mathrm{H}\right]$ vesamicol binding distributions, the pattern of these two putative presynaptic markers was qualitatively concordant within each species examined (Fig 1A). The regional density of muscarinic receptors, however, was not correlated with the level of the presynaptic markers (Fig 1B).

The interpeduncular nucleus has the highest levels of both vesamicol and hemicholinium-3 binding of the quantified regions, with the exception of hemicholinium3 binding in Rousettus egypticus, in which the nucleus was not reliably represented in the sections assayed. The striatum and basolateral amygdala have the next highest levels, with lower levels of binding observed in the hippocampal formation, neocortex, and superior colliculus. Lowest levels of binding were observed in the ventral

Table I. Inter-Species Correlation Analyses of Cholinergic Marker Distributions ${ }^{a}$

\begin{tabular}{lccc}
\hline & Vesamicol & $\begin{array}{c}\text { Hemicholin- } \\
\text { ium-3 }\end{array}$ & Scopolamine \\
\hline $\begin{array}{l}\text { Whispering Bat } \\
\text { (C. perspicalata) }\end{array}$ & $0.565^{\circ}$ & 0.783 & 0.849 \\
$\begin{array}{l}\text { Tomb Bat } \\
\text { (R. egypticus) }\end{array}$ & 0.942 & 0.810 & 0.894 \\
$\begin{array}{l}\text { Shrew } \\
\text { (B. Brevicauda) }\end{array}$ & 0.827 & 0.997 & 0.885 \\
\hline
\end{tabular}

"Values are correlation coefficients $\left(\mathrm{r}^{2}\right)$ resulting from linear regression analyses of ligand binding in tat $(R$. rattus) versus comparison species. All correlations are statistically significant at the $\mathrm{P}<0.001$ level, except where otherwise noted.

${ }^{b}$ Correlation significant at the $\mathrm{P}<0.01$ level. 

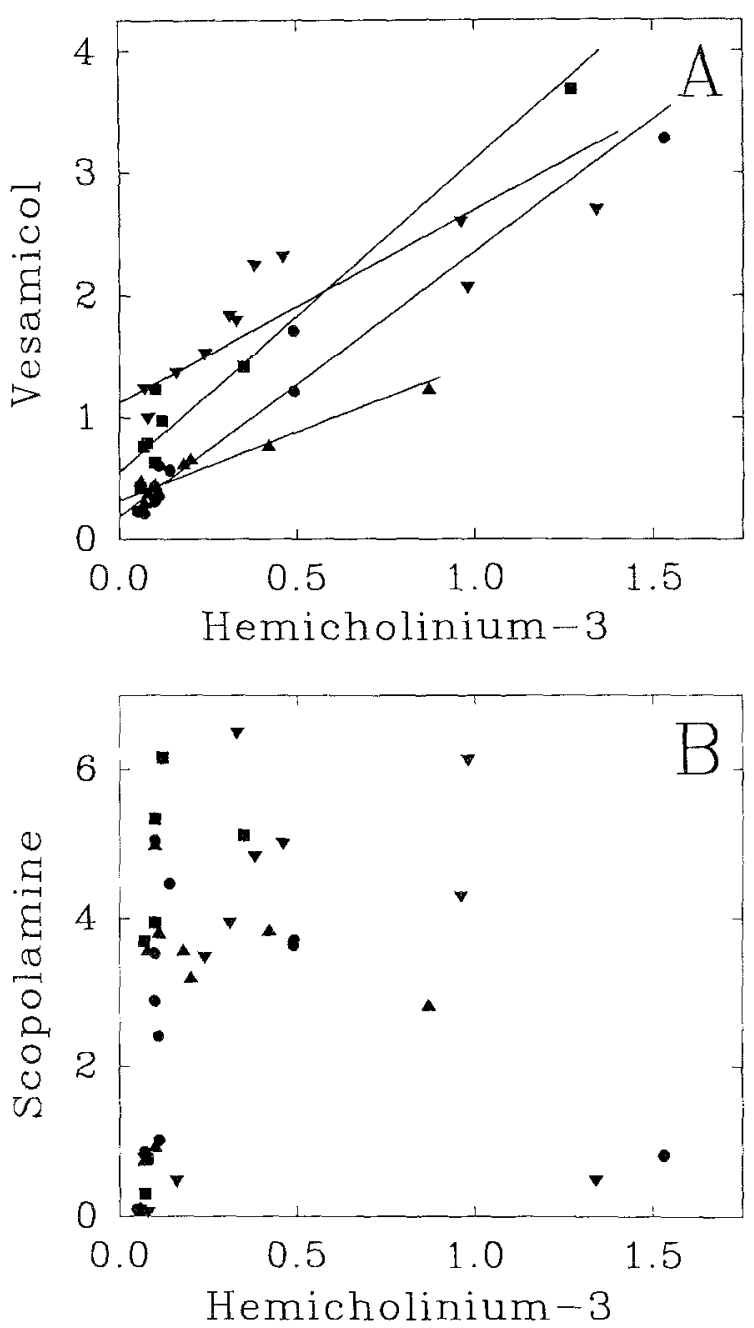

Fig. 1. Comparison of different cholinergic synaptic marker distributions within individual species. (A) Comparison of the regional binding of the presynaptic cholinergic markers hemicholinium- 3 and vesamicol within corresponding brain regions in rat (circles), shrew (squares), Tomb bat (triangles) and Whispering bat (inverted triangles) brains. Data points represent the means of ligand binding in corresponding regions, expressed as apparent fmol/ $\mu \mathrm{g}$ protein. Lines representing results of linear regression analyses for each species are additionally depicted. There is good correspondence of the two indices in each species studied (correlation coefficients: 0.71 to $0.96, \mathrm{P}<0.001$ ). A tendency for higher levels of vesamicol binding in regions with lowto-modest hemicholinium-3 binding is noted in the Whispering bat (abscissa intercept $1.12 \mathrm{fmol} / \mu \mathrm{g}$ protein) in comparison to the other species (abscissa intercepts 0.19 to $0.55 \mathrm{fmol} / \mu \mathrm{g}$ protein). (B) Comparison of presynaptic (hemicholinium-3) and predominantly postsynaptic (scopolamine) marker binding within individual species. There are no significant cotrelations $(\mathrm{P}>0.2$ to 0.6$)$ between the two indices.

and Iateral thalamic nuclei and in cerebellar cortex (Table II).

Muscarinic Receptor Distribution As detailed previously for the presynaptic cholinergic binding sites, the general pattern of muscarinic receptor binding was qualitatively similar across all of the species examined (Table I; Figs. 2-5). The CA1 hippocampal subfield, followed either by the striatum or dentate gyrus of the hippocampus have highest receptor densities in all species (Table II). The basolateral amygdala, remaining fields of the hippocampus, neocortex and superior colliculus follow in varying rank order of progressively lower receptor concentration. The ventral thalamic nuclei, interpeduncular nucleus and the cerebellum have the lowest levels of binding of the quantified regions.

\section{DISCUSSION}

The animals studied in this report were chosen to represent a broad phylogenetic spectrum. Shrews, socalled "basal" insectivores, share many similarities with primitive Jurassic mammals that are the presumed progenitors of all extant mammals, and are felt to represent the closest contemporary analogue of ancestral mammals (24). Bats, one of of the most specialized of modern mammalian orders, are additionally among the most successful, represented by a contemporary species diversity surpassed only by rodents. Although the precise sequence of mammalian phylogeny is presently unknown, paleontologic evidence indicates that bats attained modern characteristics early in the post-Cretaceous mammalian radiation and have subsequently undergone considerable morphologic diversification and adaptation (25). Thus, the representatives selected for study in the present work represent both "primitive" and "highly evolved" mammals, allowing the comparison of a diverse range of species.

Interpretation of our studies rests on the assumption that binding assays of cholinergic markers, often developed and pharmacologically characterized in rat, identify homologous binding sites in bat and shrew brains. Direct verification of this assumption would require an extensive series of pharmacologic and kinetic studies, beyond the scope of the present work. However, the binding sites under study have been examined in other species, and are found to possess similar characteristics.

The binding of hemicholinium-3, characterized initially in rodent $(17,21,22)$, has been additionally reported in studies of lagomorph (26) and primate (27) brains. The cumulative results with $\left[{ }^{3} \mathrm{H}\right]$ hemicholinium3 support the association of its saturable, high-affinity binding site with the chemically-defined presynaptic, sodium-dependent, high-affinity choline transporter. Our present results are in agreement with prior reports in other species, suggesting the presence and enrichment 
Table II. Regional Distributions of Hemicholinium-3, Vesamicol, and Scopolamine Binding Sites ${ }^{a}$

$\left[{ }^{3}\right.$ H]Hemicholinium-3 Binding

\begin{tabular}{|c|c|c|c|c|}
\hline \multirow[b]{2}{*}{$\begin{array}{l}\text { Brain } \\
\text { Region }^{b}\end{array}$} & \multicolumn{4}{|c|}{ Species } \\
\hline & $\begin{array}{l}\text { Rat } \\
(\text { R. rattus })\end{array}$ & $\begin{array}{l}\text { Whispering Bat } \\
\text { (C. perspicalata) }\end{array}$ & $\begin{array}{c}\text { Tomb Bat } \\
(R . \text { egypticus })\end{array}$ & $\begin{array}{c}\text { Shrew } \\
\text { (B. Brevicauda) }\end{array}$ \\
\hline$\overline{\text { CTX }}$ & $0.10(0.02)$ & $0.24(0.02)$ & $0.11(0.01)$ & $0.10(0.03)$ \\
\hline $\mathrm{CA} 1$ & $0.10(0.01)$ & $0.33(0.02)$ & $0.10(0.02)$ & \\
\hline $\mathrm{CA} 3$ & $0.11(0.01)$ & $0.46(0.07)^{d}$ & $0.20(0.05)$ & $0.10^{\circ}$ \\
\hline DG & $0.14(0.02)$ & $0.38(0.06)$ & $0.18(0.02)$ & $0.12^{e}$ \\
\hline STR & $0.49(0.06)^{c}$ & $0.98(0.09)$ & $0.42(0.07)$ & $0.35(0.15)$ \\
\hline BLA & $0.49(0.03)$ & $0.96(0.03)^{d}$ & $0.87(0.06)^{c}$ & \\
\hline VTH & $0.07(0.01)$ & $0.07(0.01)$ & $0.07(0.01)^{c}$ & $0.07(0.03)$ \\
\hline $\mathrm{SC}$ & $0.11(0.02)$ & $0.16(0.01)$ & $0.10(0.01)^{c}$ & $0.08^{c}$ \\
\hline IPN & $1.53(0.20)^{d}$ & $1.34(0.61)^{d}$ & & $1.27^{e}$ \\
\hline CBL & $0.05(0.01)$ & $0.08(0.02)$ & $0.06(0.01)$ & $0.06(0.01)$ \\
\hline
\end{tabular}

$\left[{ }^{3} \mathrm{H}\right]$ Vesamicol Binding

\begin{tabular}{|c|c|c|c|c|}
\hline \multirow[b]{2}{*}{$\begin{array}{l}\text { Brain } \\
\text { Region }\end{array}$} & \multicolumn{4}{|c|}{ Species } \\
\hline & $\begin{array}{l}\text { Rat } \\
(\text { R. rattus })\end{array}$ & $\begin{array}{l}\text { Whispering Bat } \\
\text { (C. perspicalata) }\end{array}$ & $\begin{array}{c}\text { Tomb Bat } \\
(R . \text { egypticus })\end{array}$ & $\begin{array}{c}\text { Shrew } \\
\text { (B. Brevicauda) }\end{array}$ \\
\hline CTX & $0.33(0.04)$ & $1.53(0.35)$ & $0.38(0.11)$ & $0.63(0.19)$ \\
\hline CA1 & $0.43(0.08)$ & $1.80(0.15)$ & $0.42(0.15)$ & $0.72(0.22)$ \\
\hline $\mathrm{CA} 3$ & $0.60(0.14)$ & $2.32(0.14)$ & $0.65(0.13)$ & $1.23(0.19)$ \\
\hline DG & $0.57(0.09)$ & $2.25(0.26)$ & $0.61(0.12)^{c}$ & $0.97(0.28)$ \\
\hline STR & $1.21(0.20)$ & $2.07(0.12)$ & $0.76(0.13)$ & $1.42^{e}$ \\
\hline BLA & $1.71(0.30)$ & $2.60(0.15)^{c}$ & $1.23(0.34)$ & $0.87^{e}$ \\
\hline VTH & $0.21(0.08)$ & $1.24(0.31)$ & $0.29(0.14)$ & \\
\hline SC & $0.35(0.03)$ & $1.38(0.45)$ & $0.44(0.13)^{c}$ & $0.79(0.25)$ \\
\hline IPN & $3.28(0.38)^{d}$ & $2.70(0.14)^{c}$ & $1.59(0.64)^{c}$ & $3.69^{e}$ \\
\hline $\mathrm{CBL}$ & $0.23(0.06)$ & $1.00(0.42)$ & $0.47(0.15)$ & $0.42(0.03)$ \\
\hline
\end{tabular}

$\left[{ }^{3} \mathrm{H}\right]$ Scopolamine Binding

\begin{tabular}{|c|c|c|c|c|}
\hline \multirow[b]{2}{*}{$\begin{array}{l}\text { Brain } \\
\text { Region }^{b}\end{array}$} & \multicolumn{4}{|c|}{ Species } \\
\hline & $\begin{array}{l}\text { Rat } \\
\text { (R. rattus) }\end{array}$ & $\begin{array}{l}\text { Whispering Bat } \\
\text { (C. perspicalata) }\end{array}$ & $\begin{array}{c}\text { Tomb Bat } \\
\text { (R. egypticus) }\end{array}$ & $\begin{array}{c}\text { Shrew } \\
\text { (B. Brevicauda) }\end{array}$ \\
\hline CTX & $2.89(0.26)$ & $3.49(0.47)$ & $3.80(0.30)^{c}$ & $3.94(0.05)$ \\
\hline CA1 & $5.05(0.21)$ & $6.50(1.25)$ & $4.98(2.03)$ & $7.29(0.44)$ \\
\hline CA3 & $2.41(0.10)$ & $5.02(0.71)$ & $3.19(1.15)$ & $5.34(0.14)$ \\
\hline DG & $4.47(0.16)$ & $4.85(0.43)$ & $3.56(1.33)$ & $6.16(0.02)$ \\
\hline STR & $3.71(0.46)$ & $6.14(0.59)^{d}$ & $3.83(0.42)$ & $5.12(0.15)$ \\
\hline BLA & $3.64(0.37)^{c}$ & $4.31(0.32)^{d}$ & $2.82(1.17)$ & \\
\hline VTH & $0.85(0.10)$ & $0.78(0.08)^{c}$ & $0.73(0.25)$ & $0.30^{e}$ \\
\hline $\mathrm{SC}$ & $1.02(0.07)$ & $0.48(0.07)$ & $0.92(0.02)^{c}$ & $0.77(0.11)$ \\
\hline IPN & $0.82(0.33)$ & $0.49(0.36)^{c}$ & $0.63(0.23)^{c}$ & \\
\hline CBL & $0.09(0.01)$ & $0.07(0.06)^{c}$ & $0.10(0.02)$ & $0.08(0.01)$ \\
\hline
\end{tabular}

${ }^{a}$ Values represent means (SD) of radioligand binding, expressed in units of apparent fmol/ $\mu \mathrm{g}$ protein, as determined from densitometric analyses of autoradiograms from brains of rat, Whispering bat, Tomb bat $(n=4$ each), and shrew $(n=2)$.

${ }^{b}$ Anatomic abbreviations as in the legend to Fig. 2

${ }^{c} \mathrm{n}=3$ subjects

${ }^{d} \mathrm{n}=2$ subjects

${ }^{e} \mathrm{n}=1$ subject

of hemicholinium-3 binding sites in putative cholinergic synaptic terminal fields.

Vesamicol binding to the cholinergic presynaptic vesicle was originally described in preparations from the electric organ of Torpedo californicus (28), and subsequently evaluated in greater detail in rat brain (20). The 


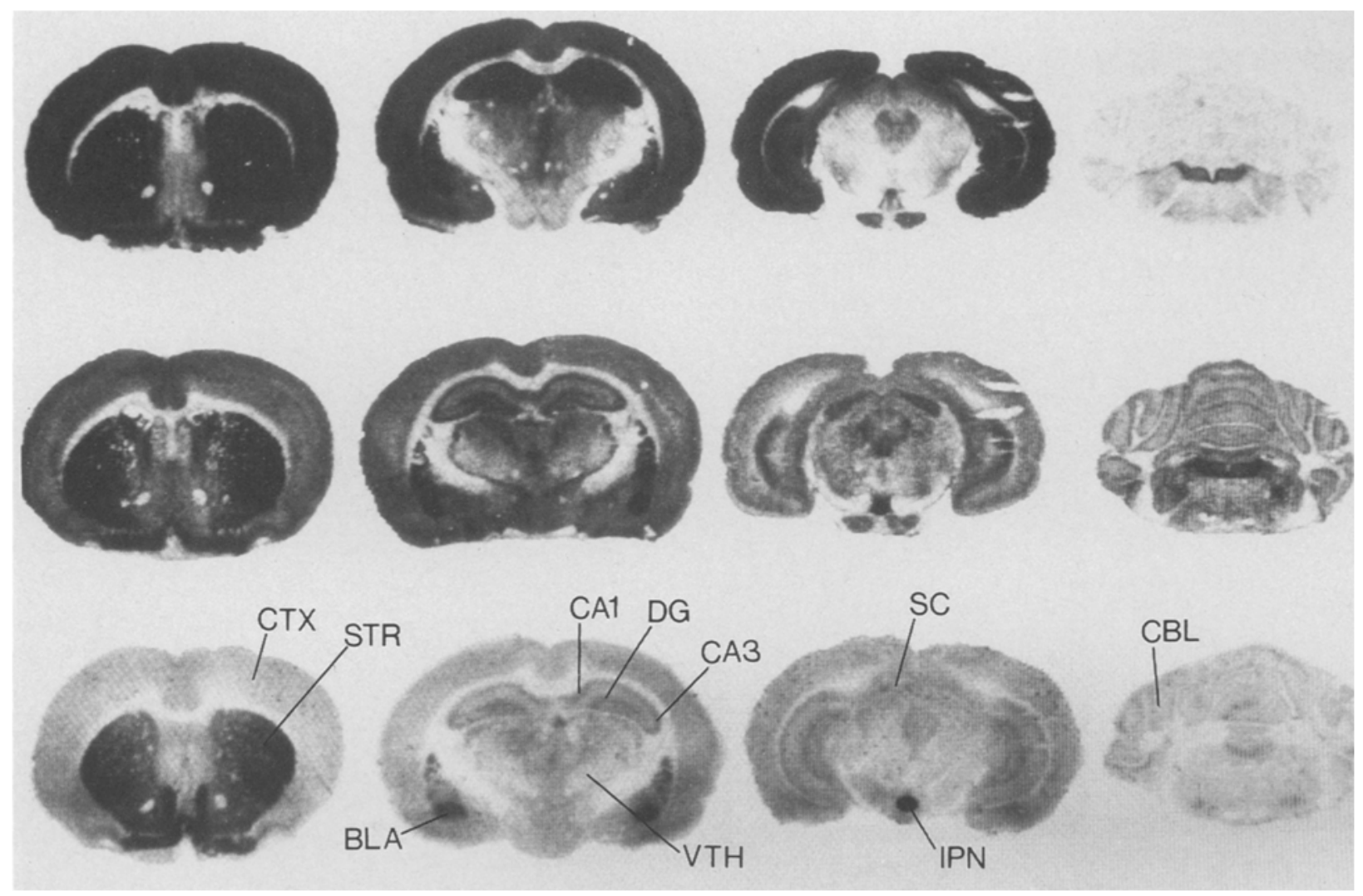

Fig. 2. Autoradiographic distributions of cholinergic markers in the rat brain. Coronal brain sections from comparable levels of the rat brain depict the binding of $\left[{ }^{3} \mathrm{H}\right]$ scopolamine (top row), $\left[{ }^{3} \mathrm{H}\right]$ vesamicol (middle row) and $\left[{ }^{3} \mathrm{H}\right]$ hemicholinium-3 (bottom row). Anatomic levels range from rostral (left column) to caudal (right column) for each marker. Anatomic regions quantified by densitometry are indicated in the hemicholinium-3 images: CTX-cerebral cortex; STR-striatum; BLA-basolateral amygdala; CA1 and CA3-hippocampal subfields; DG-dentate gyrus of the hippocampus; VTH-ventral thalamus; IPN-interpeduncular nucleus; SC-superficial superior colliculus; CBL-cerebellum.

basic characteristics of binding and competition by unlabeled drugs are conserved across these studies, suggesting wide phylogenetic conservation of the cholinergic presynaptic vesicle and at least some of its individual protein constituents. Limited studies have been conducted with $\left[{ }^{3} \mathrm{H}\right]$ vesamicol in human postmortem samples $(29,30)$ which suggest a distribution of the binding site similar to that described in rat brain. The results obtained in the current sample of mammalian brains further support the association of $\left[{ }^{3} \mathrm{H}\right]$ vesamicol binding sites with cholinergic presynaptic terminals, on the basis of the regional pattern of binding. It is notable, however, that a substantial diffuse background binding of vesamicol binding is found in the Whispering bat, relative to other species. This may reflect a component of binding to a secondary, unrelated (non-cholinergic) site, termed the vesamicol binding protein (31).

Muscarinic cholinergic receptors have been studied in a few non-mammalian species (32-34), and found to have properties similar to those defined in rat brain, indicating phylogenetic conservation of this binding site. The pharmacologic profile of $\left[{ }^{3} \mathrm{H}\right]$ quinuclidinyl benzilate binding is comparable, for instance, between the house fly head and the rat brain (35). The regional distribution of muscarinic receptors has been reported in a variety of mammalian brains, including rat $(18,36,37)$, monkey (38), and human (39). Our current findings are in agreement with these prior studies, indicating high concentrations of receptors in most forebrain regions receiving cholinergic input (see below).

Cholinergic pathways of the central nervous system have been extensively studied in rat $(8,9)$ and to a lesser extent in monkey (7) and cat (6). Cholinergic innervation of the cerebral cortex is provided by basal forebrain magnocellular neurons, which project to the hippocampal formation, neocortex, amygdala, and olfactory bulb. A similar organization is indicated for the species studied in the present report, on the bases of presynaptic cholin- 


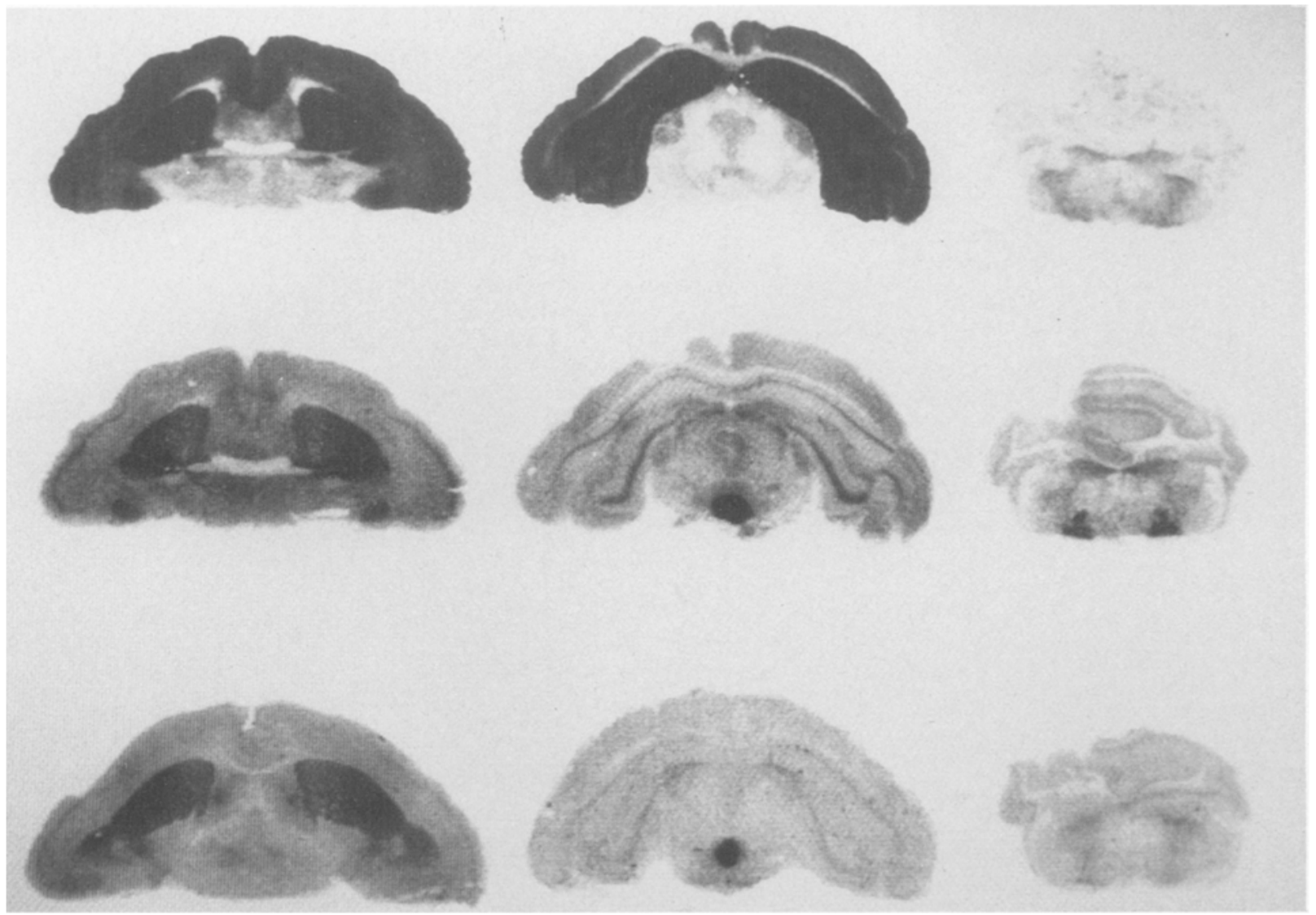

Fig. 3. Autoradiographic distributions of cholinergic markers in the shrew brain. Scopolamine, vesamicol, and hemicholinium-3 binding are depicted in the top through bottom rows, respectively. The left column of sections is at the level of the striatum, the middle column is at the level of the interpeduncular nucleus, and the right column is at the cerebellar level. Intense, focal vesamicol binding is observed in the nuclei of the facial nerve (ventral aspect of the middle section in the right-most column). Comparable hemicholinium-3 binding is not evident, since the nuclei are not present in the more caudal section at the bottom right.

ergic markers identified in neocortical and hippocampal regions.

A dense plexus of innervation, arising from cholinergic interneurons, is an outstanding feature of the striatum (caudate nucleus, nucleus accumbens, putamen, and olfactory tubercle) in all mammalian species examined to date. This accounts for the high striatal levels of cholinergic markers including cholineacetyltransferase, acetylcholinesterase, high-affinity choline uptake, and of the transmitter acetylcholine itself (40). Our present results confirm that this aspect of striatal neurochemistry is representative of most mammalian brains, since the striatum is among the highest in levels of hemicholinium-3 and vesamicol binding sites observed.

Brainstem cholinergic nuclei include the centrallyprojecting pontine paramedian and paraventricular nuclei $(41,42)$, as well as nuclei of motor cranial nerves. The former group sends ascending projections to thalamic and subcortical telencephalic targets. These nuclei and their terminal fields were not represented regularly in the tissues examined in the present, and were thus not subjected to quantification. Nevertheless, anterior and intralaminar thalamic nuclei as well as motor cranial nerve nuclei were identified sporadically in our data sets, distinguished by both pre- and postsynaptic cholinergic indices. Future studies will require more intensive anatomic sampling to better define these nuclei and projections.

Finally, our results identify a number of areas with discordant pre- and postsynaptic indices, particularly evident in diencephalic and brainstem nuclei. These regions are exemplified by the interpeduncular nucleus, which expresses intense presynaptic marker labeling. Efferent cholinergic fibers are believed to originate within, or alternatively traverse via fibers of passage, the ha- 


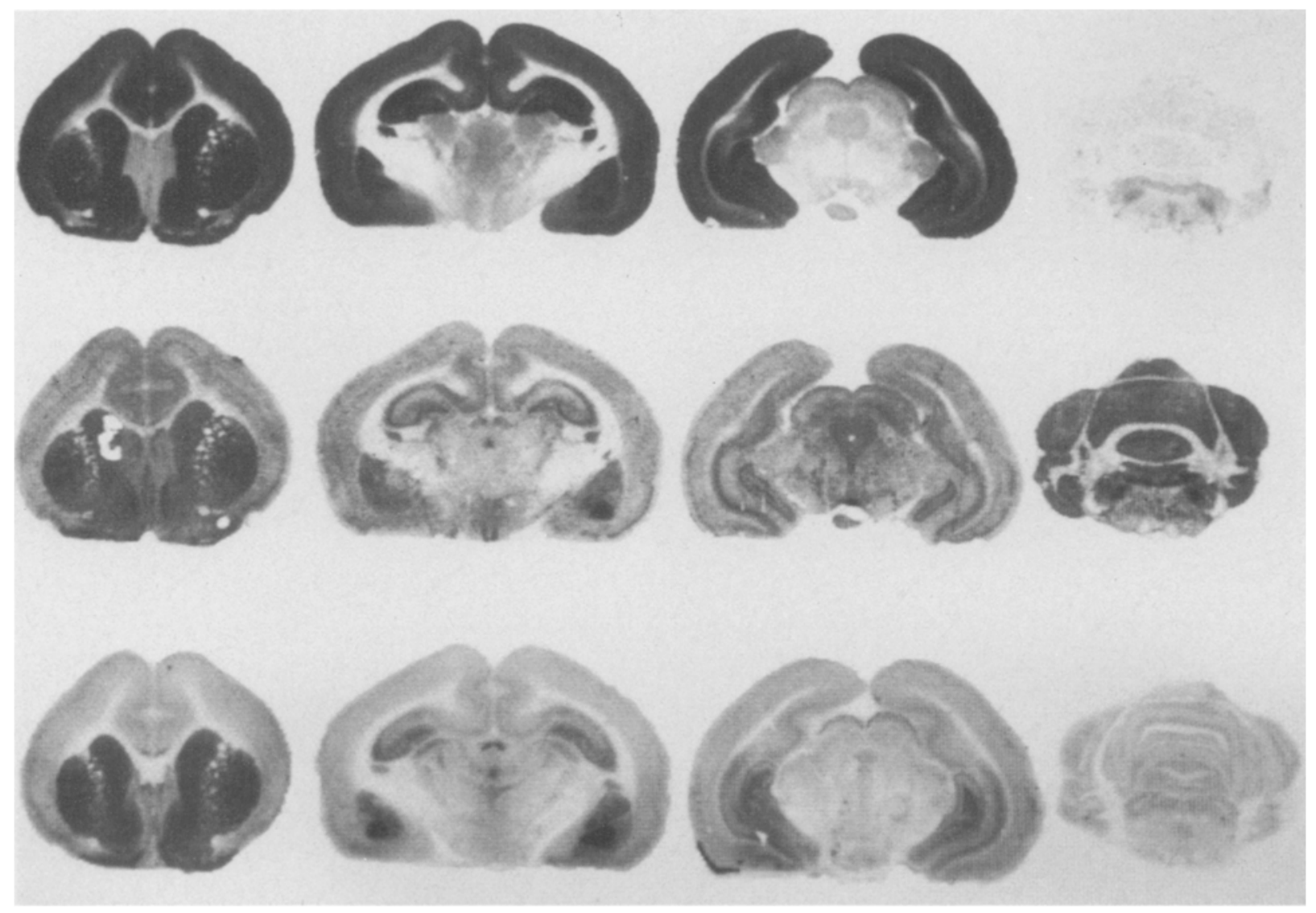

Fig. 4. Autoradiographic distributions of cholinergic markers in the Tomb bat brain. Scopolamine, vesamicol, and hemicholinium-3 binding are depicted in the top through bottom rows, respectively. The rostro-caudal levels of each of the columns correspond to the levels depicted in Fig. 2 , with the exception that the interpeduncular nucleus is not well-represented (third column of sections) at this slightly more caudal level than that represented in the rat autoradiograms.

benula, and further travel in the habenulo-interpeduncular tract (8). We observed high levels of both presynaptic binding sites in our studies, despite only minor levels of muscarinic receptors. This apparent mismatch may indicate distinct expression levels or regulation of the muscarinic receptor populations across brain regions, or may indicate predominance of nicotinic postsynaptic mechanisms in the interpeduncular system (43). Many of the areas with varying degree of apparent mismatch are known to express high levels of nicotinic acetylcholine receptors, including the interpeduncular nucleus, dorsal thalamus and the superior and inferior colliculi (44).

In summary, the present results suggest that the organization of cholinergic pathways in two species of bat and one shrew is similar to that of the rat. Both cholinergic innervation and muscarinic cholinergic receptor distribution patterns are similar in these four phy- logenetically diverse mammals. In further preliminary experiments, we have found a corresponding anatomic distribution of pre- and postsynaptic markers in the brain of a marsupial (the Virginia opossum, Didelphis virginiana). As the organization of cholinergic pathways of the rodent is similar to that of primate and carnivore, the combined data suggest that its general features are characteristic of all eutherian mammals. Furthermore, as some data indicate differences between mammals and reptiles in the distribution of cholinergic neuropil within the striatal and hippocampal homologues, it is likely that the pattern of cholinergic organization observed in our studies is unique to the mammalian radiation. The strong conservation of anatomic homology in cerebral cholinergic pathways among mammals suggests that the functions subserved by cholinergic activity may also be similar, although further pharmacologic and physiologic studies will be necessary to explore this hypothesis. 


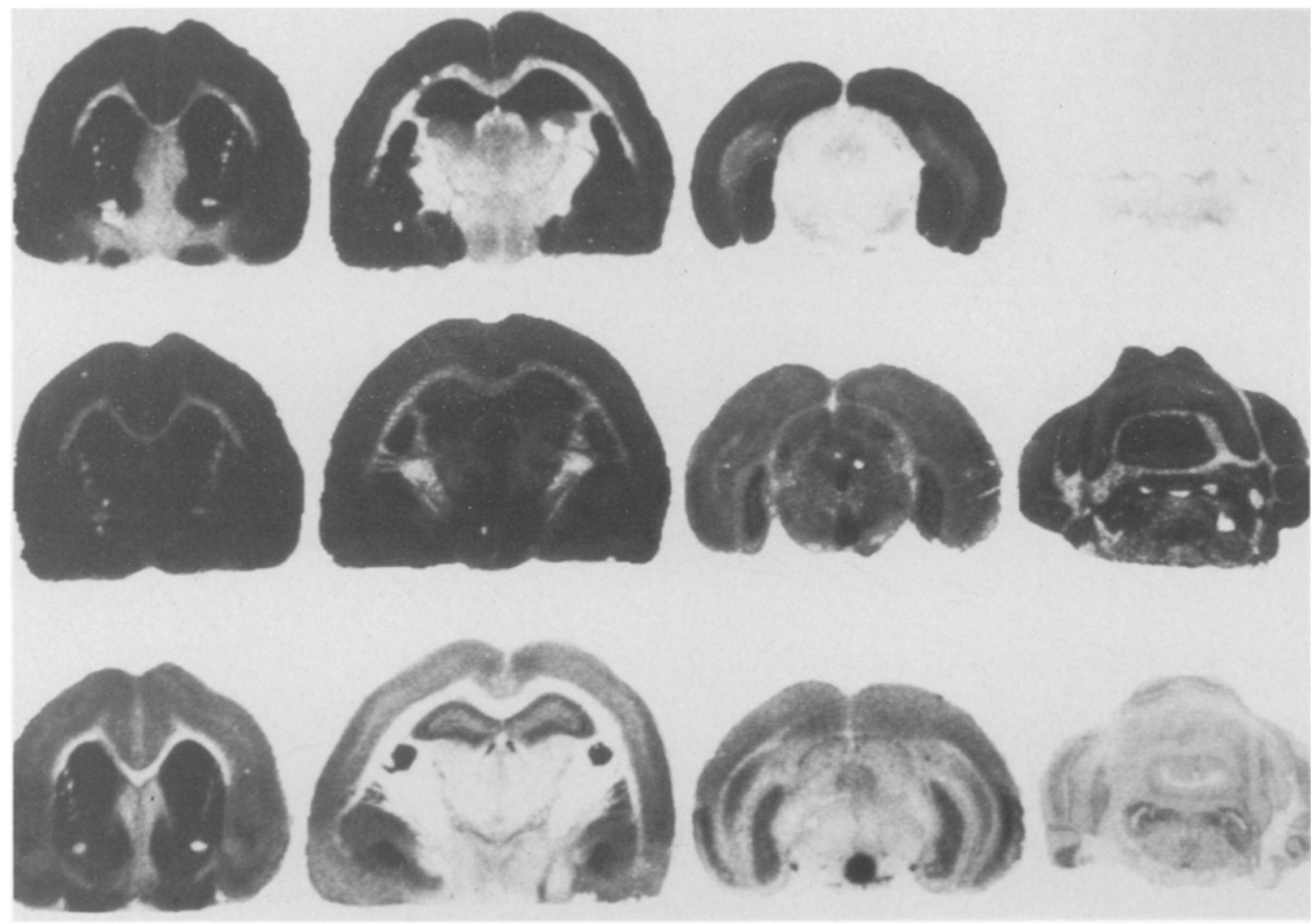

Fig. 5. Autoradiographic distributions of cholinergic markers in the Whispering bat brain. Scopolamine, vesamicol, and hemicholinium-3 binding are depicted in the top through bottom rows, respectively. The rostro-caudal levels of each of the columns correspond to the levels depicted in Fig. 2. Note the generally higher levels of vesamicol binding in regions of low-to-moderate hemicholinium-3 binding (cerebral cortex, thalamus, cerebellum) than are observed in the other species studied.

\section{ACKNOWLEDGMENTS}

These studies were supported by grants designated P01 MH42652 and P01 NS19613 from The National Institute of Mental Health and The National Institutes of Health, respectively. We are indebted to Dr. Roderick Suthers (Indiana University) for providing the bats and to Dr. Phillip Myers (The University of Michigan) for providing the shrews used in these studies.

\section{REFERENCES}

1. Bartus, R. T., Dean, R. L., Beer, B., and Lippa, A. S. 1982. The cholinergic hypothesis of geriatric memory dysfunction. Science 217:408-417.

2. Whitehouse, P. J., Price, D. L., Clark, A. W., Coyle, J. T., and DeLong, M. R. 1981. Alzheimer disease: Evidence for selective loss of cholinergic neurons in the nucleus basalis. Ann. Neurol. $10: 122-126$.

3. Fahn, S. 1983. High dosage anticholinergic therapy in dystonia. Neurology 33:1255-1261.
4. Quattrochi, J. J., Mamelak, A. N., Madison, R. D., Macklis, J. D., and Hobson, J. A. 1989. Mapping neuronal inputs to REM sleep induction sites with carbachol-fluorescent microspheres. Science 245:984-986.

5. Wachtler, K. 1988. Phylogeny of the cholinergic synapse. Pages 57-80, in Whittaker, V. P. (ed.), The Cholinergic Synapse, Springer-Verlag, Berlin.

6. Kimura, H., McGeer, P. I., Peng, J. H., and McGeer, E. G. 1981. The central cholinergic system studied by choline acetyltransferase immunohistochemistry in the cat. J. Comp. Neurol. 200:151-201.

7. Mesulam, M. M., Mufson, E. J., Levey, A. I., and Wainer, B. H. 1984. Atlas of cholinergic neurons in the forebrain and upper brainstem of the macaque based on monoclonal choline acetyltransferase immunohistochemistry and acetylcholinesterase histochemistry. Neurosci. 12:669-686.

8. Fibiger, H. C. 1982. The organization and some projections of cholinergic neurons of the mammalian forebrain. Brain Res. Rev. $4: 327-388$.

9. Mesulam, M.-M., Mufson, E. J., Wainer, B. H., and Levy, A. I. 1983. Central cholinergic pathways in the rat: An overview based on an alternative nomer-lature (CH1-CH6). Neuroscience 10:1185-1201.

10. Johnston, M. V., McKinney, M., and Coyle, J. T. 1981. Neo- 
cortical cholinergic innervation: A description of extrinsic and intrinsic components in the rat. Exp. Brain Res. 43:159-172.

11. Hoogland, P. V., and Vermeulen-VanderZee, E. 1990. Distribution of choline acetyltransferase immunoreactivity in the telencephalon of the lizard Gekko gecko. Brain Behav. Evol. 36:378390.

12. Brauth, S. E., Kitt, C. A., Price, D. L., and Wainer, B. H. 1985. Cholinergic neurons in the telencephalon of the reptile caiman crocodilus. Neurosci. Letters 58:235-240.

13. Mufson, E. J., Desan, P. H., Mesulam, M. M., Wainer, B. H., and Levey, A. I. 1984. Choline acetyltransferase-like immunoreactivity in the forebrain of the red-eared pond turtle (Pseudemys scripta elegars). Brain Res. 323:103-108.

14. Stoof, J. C., Russchen, F. T., Verheijden, P. F. H. M., and Hoogland, P. V. J. M. 1987. A comparative study of the dopamine-acetylcholine interaction in telencephalic structures of the rat and of a reptile, the lizard Gekko gecko. Brain Res, 404:273281.

15. Henselmans, J. M. L., Hoogland, P. V., and Stoof, J. C. 1991. Differences in the regulation of acetylcholine release upon $D_{2}$ dopamine and $\mathrm{N}$-methyl-D-aspartate receptor activation between the striatal complex of reptiles and the neostriatum of rats. Brain Res. 566:8-12.

16. Parsons, S. M., Prior, C., and Marshall, I. G. 1993. Acetylcholine transport, storage, and release. Int. Rev. Neurobiol 35:279390.

17. Happe, H. K., and Murrin, L. C. 1993. High affinity choline transport sites: use of [ $\left.{ }^{3} \mathrm{H}\right]$ hemicholinium-3 as a quantitative marker. J. Neurochem. 60:1191-1201.

18. Frey, K. A., and Howland, M. M. 1992. Quantitative autoradiography of muscarinic cholinergic receptor binding in the rat brain: Distinction of receptor subtypes in antagonist competition assays. J. Pharmacology and Experimenta! Therapeutics. 263:3:1391-1400.

19. Marien, M. R., Parsons, S. M., and Altar, C. A. 1987. Quantitative autoradiography of brain binding sites for the vesicular acetylcholine transport blocker 2-(4-phenylpiperidino) cyclohexanol (AH5183). Proc. Natl. Acad. Sci. USA 84:876-880.

20. Altar, C. A., and Marien, M. R. 1988. [ ${ }^{3}$ H] Vesamicol binding in brain; autoradiographic distribution, pharmacology, and effects of cholinergic lesions. Synapse 2:486-493.

21. Rainbow, T. C., Parsons, B., and Wieczorek, C. M. 1984. Quantitative autoradiography of $\left.{ }^{3} \mathrm{H}\right]$ hemicholinium-3 binding sites in rat brain. Eur. J. Pharmacol. 102:195-196.

22. Vickroy, T. W., Roeske, W. R., Gehlert, D. R., Wamsley, J. K., and Yamamura, H. I. 1985. Quantitative light microscopic autoradiography of $\left[{ }^{3} \mathrm{H}\right]$ hemicholinium-3 binding sites in the rat central nervous system: A novel biochemical marker for mapping the distribution of cholinergic nerve terminals. Brain Res. 329:368373.

23. Pan, H. S., Frey, K. A., Young, A. B., and Penney, J. B., Jr. 1983. Changes in $\left[{ }^{3} \mathrm{H}\right]$ muscimol binding in substantia nigra, entopeduncular nucleus, globus pallidus, and thalamus after striatal lesions as demonstrated by quantitative receptor autoradiography. J. Neurosci. 3:1189-1198.

24. Carroll, R. L. 1988. Vertebrate Paleontology and Evolution, W. H. Freeman, San Francisco.

25. Novacek, M. J. 1985 . Evidence for echolocation in the oldest known bats. Nature 315(6015):140-141.

26. Rhodes, K. J., Joyce, J. N., Sapp, D. W., and Marshall, J. F. 1987. $\left[{ }^{3} \mathrm{H}\right]$ Hemicholinium-3 binding in rabbit striatum: Correspondence with patchy acetylcholinesterase staining and a method for quantifying striatal compartments. Brain Res. 412:400-404.

27. Lowenstein, P. R., Slesinger, P. A., Singer, H. S., Walker, L. C., Casanova, M. F., Pricc, D. L., and Coyle, J. T. 1987. An autoradiographic study of the development of $\left[{ }^{3} \mathrm{H}\right]$ hemicholinium-
3 binding sites in human and baboon basal ganglia: A marker for the sodium-dependent high affinity choline uptake system. Dev. Brain Res. 34:291-297.

28. Bahr, B. A., and Parsons, S. M. 1986. Demonstration of a receptor in Torpedo synaptic vesicles for the acetylcholine storage blocker L-trans-2-(4-phenyl[3,4-3 $\mathrm{H}$-piperidino) cyclohexano 1. Proc. Natl. Acad. Sci. U. S. A. 83:2267-2270.

29. Ruberg, M., Mayo, W., Brice, A., Duyckaerts, C., Hauw, J. J., Simon, H, LeMoal, M., and Agid, Y. 1990. Choline acetyltransferase activity and $\left[{ }^{3} \mathrm{H}\right]$ vesamicol binding in the temporal cortex of patients with Alzheimer's discase, Parkinson"s disease, and rats with basal forcbrain lesions. Neuroscience 35:327-333.

30. Kisch, S. I., Distefano, L. M., Dozic, S., Robitaille, Y., Rajput, A., Deck, J. H. N., and Hornykiewicz, O. 1990. [3H] Vesamicol binding in human brain cholinergic deficiency disorders. Neurosci. Lett. 117:347-352.

31. Hicks, B. W., Rogers, G. A., and Parsons, S. M. 1991. Purification and characterization of a nonvesicular vesamicol binding protein from electric organ and demonstration of a related protein in mammalian brain. J. Neurochem. 57:509-519.

32. Dietl, M. M., Cortes, R., and Palacios, J. M. 1988. Neurotransmitter receptors in the avian brain. Il. Muscarinic cholinergic receptors. Brain Res, 439:360-365.

33. Schlegel, J. R., Kriegstein, A. R. 1987. Quantitative autoradiography of muscarinic and benzodiazepine receptors in the forebrain of the turtle, Pseudemys scripta. J. Comp. Neurol. 265:521-529.

34. Wachtler, K. 1985. Regional distribution of muscarinic acetylcholine receptors in the telencephalon of the pigeon (Columbia livia $f$. domestica). J. Hirnforsch. 26:85-89.

35. Jones, S. W., and Sumikawa, K. 1981. Quinuclidinyl benzilate binding in house fly heads and rat brain. J. Neurochem. 36:454 459 .

36. Rotter, A., Birdsall, N. J. M., Burgen, A. S. V., Field, P. M., Hulme, E. C., and Raisman, G. 1979. Muscarinic receptors in the central nervous system of the rat. I. Technique for autoradiographic localization of the binding of $\left[{ }^{3} \mathrm{H}\right]$ propylbenzylcholine mustard and its distribution in forebrain. Brain Res. Rev. 1:141165.

37. Cortes, R., and Pacacios, J. M. 1986. Muscarinic receptor subtypes in the rat brain. I, Quantitative autoradiographic studies. Brain Res. 362:227-238.

38. Miyoshi, R., Kito, S., and Shimoyama, M. 1989. Quantitative autoradiographic localization of the M1 and M2 subtypes of muscarinic acetylcholine receptors in the monkey brain. Jpn. J. Pharmacol. 51:247-255.

39. Lin, S.-C., Olson, K. C., Okazaki, H., and Richelson, E. 1986. Studies on muscarinic binding sites in human brain identified with [3H]pirenzepine. J. Neurochem. 46:274-279.

40. McGeer, P. L., McGeer, E. G., Fibiger, H. C., and Wickson, V. 1971. Neostriatal choline acetylase and cholinesterase following selective brain lesions. Brain Res. 35:308-314.

41. Lec, H. J., Rye, D. B., Hallanger, A. E., Levey, A. I., and Wainer, B. H. 1988. Cholinergic vs. Noncholinergic efferents from the mesopontine tegmentum to the extrapyramidal motor system nuclei. J. Comp. Neurol. 275:469-492.

42. Woolf, N. J., and Butcher, L. L. 1986. Cholinergic systems in the rat brain: III. Projections from the ponto mesencephalic tegmentum to the thalamus, tectum, basal ganglia, and basal fore. brain. Brain Res. Bull. 16:603-637.

43. Lena, C., Changeux, J.-P., and Mulle, C. 1993. Evidence for "preterminal" nicotinic receptors on BABAergic axons in the rat interpeduncular nucleus. J. Neurosci. 13:2680-2688.

44. Clarke, P. B. S., Schwariz, R. D., Paul, S. M., Pert, C. B., and Pert, A. 1985. Nicotinic binding in rat brain: Autoradiographic comparison of $\left[{ }^{3} \mathrm{H}\right]$ acetylcholine, $\left[{ }^{3} \mathrm{H}\right]$ nicotine, and $\left[{ }^{125} \mathrm{I}\right]-\alpha-b u n-$ garotoxin. J. Neurosci. 5:1307-1315. 